\title{
The Bayh-Dole Act and university research and development
}

\author{
Matthew Rafferty* \\ Department of Economics, Quinnipiac University, Hamden, CT 06518-1965, United States
}

Received 25 October 2004; received in revised form 10 June 2006; accepted 13 June 2007

Available online 21 December 2007

\begin{abstract}
This paper examines the relationship between university research and development $(R \& D)$ activities and the Bayh-Dole Act. This act made it much easier for universities to obtain patents from research funded by the federal government and may have provided universities with an incentive to alter their R\&D activities. The Act may provide an incentive to reduce basic research (which does not generate licensing fees) and increase applied research (which does generate patents and licensing fees). In addition, industry might be more willing to fund university R\&D projects since the results would now be easier to patent. This paper differs from the existing literature which uses patent data (a measure of research output) by using research and development data (a measure of inventive input) to examine the effect of the Act.
\end{abstract}

(c) 2007 Elsevier B.V. All rights reserved.

Keywords: Bayh-Dole Act; Research and development

\section{Introduction}

Universities have always conducted applied research in conjunction with industry or the government. However, historically federal legislation made it very difficult for universities to patent the results of research funded by the federal government. In 1980, this changed. The Bayh-Dole Patent and Trademark Amendments Act of 1980 allowed universities to receive patents and grant licenses, even exclusive licenses, on patents resulting from research funded by the federal government. At the time of the Act, many people thought that there was a large pool of un-commercialized discoveries from federally funded research due to the difficulty of obtaining patents on such research. The goal of the act was to provide universities with a financial incentive to tap this pool. The hope was that faster commercialization would

\footnotetext{
* Tel.: +1 203582 3396; fax: +1 2035828664 .

E-mail address: matthew.rafferty@ quinnipiac.edu.
}

mean the benefits of university research would reach the consumer more quickly.

The Bayh-Dole Act may have succeeded too well. One could argue that the Bayh-Dole Act has led universities to de-emphasize basic research, which does not generate revenues for the university, and pursue applied research, which generates revenues from licensing fees on patents. This could show up in a reduction in basic $R \& D$ activity at universities or a decline in the quality of university patents. If either of these occurred, the Act would have had the perverse effect of slowing the expansion of the scientific frontier which might hurt consumers even if existing discoveries are commercialized more quickly.

This paper examines the validity of this criticism of the Bayh-Dole Act using standard time-series models and both conventional and endogenous structural break tests. If the Bayh-Dole Act led universities and colleges to alter research behavior then one would expect a structural break in the time-series model for university research and development (R\&D) data. Section 2 of 
this paper reviews the relevant literature and points out that most of the existing research uses patent data rather than $R \& D$ data to determine the effect of the Bayh-Dole Act. Section 3 examines if there is a change in the composition of R\&D performed and funded by colleges and universities. This section also examines industry funding of $R \& D$ activities in colleges and universities. Section 4 estimates time-series models for university level $R \& D$ data and tests for structural breaks in the time-series models. Section 5 concludes.

\section{Literature review and theoretical issues}

Henderson et al. (1998) use patent citation data to examine the effect of the Bayh-Dole Act on university research. Their data consisted of a random sample of one percent of all patents to determine the importance (frequency with which a patent is cited by subsequent patents) and generality (the range of subsequent patent types which cite a particular patent) of university patents. Patents arising from basic research should be both important and general while patents arising from applied research should be both less important and less general. Henderson et al. (1998) find that both the importance and generality of university patents have declined compared to other patents. This is consistent with the view that universities have shifted their focus from basic research to applied research. In addition, Coupe (2003) argues that since the Bayh-Dole Act colleges and universities have begun to apply for patents with the same frequency as commercial firms suggesting that universities and colleges have become more interested in the revenues from licensing their patents.

The interpretation that the Bayh-Dole Act has led to a decline in the quality of university and college patents is subject to several criticisms. First, Mowery et al. (2001) note that university and college involvement in applied research is not a recent phenomenon and that the rise in patenting activity by universities and colleges predates the passage of the Bayh-Dole Act. They show that the University of California and Stanford patent activity accelerated in the 1970s in tandem with the rise in biomedical and pharmaceutical research. In addition, these areas of research lie in Pasteur's Quadrant as defined by Stokes (1997) which means that even basic research has commercial applications. Therefore, Mowery et al. (2001) interpret the surge in patenting activity as at least partially driven by technological factors rather than the Bayh-Dole Act.

Second, the decline in patent quality may not be as significant as Henderson et al. (1998) believe. Because subsequent patents are used to determine the quality of current patents a truncation problem exists with the procedure of Henderson et al. (1998) as they themselves acknowledge. If one considers a short time span then patents may appear to be low quality patents because not enough time has passed for researchers to cite the patent. Mowery and Ziedonis (2002) find that the importance and generality of patents from the University of California and Stanford did not decline significantly after the passage of the Bayh-Dole Act once one considers a longer time span of data. The result is not limited to just the top universities. Mowery and Ziedonis (2002) reached a similar conclusion for universities with at least ten patent citations during the five years prior to the passage of the Bayh-Dole Act. Sampat et al. (2003) also find that patent quality does not decline once the truncation bias and changes in the temporal distribution of patent citations are accounted for. The results in these papers suggest the quality of university and college patents has not declined since the passage of the Bayh-Dole Act.

Third, Jensen and Thursby (2001) survey universities and find that most licensing occurs at the early stage of a technology before commercial applications are often clear. They point out that over $75 \%$ of licensed inventions were at the proof of concept stage or only had a lab scale prototype available. Just $12 \%$ of licensed inventions were ready for commercial sale and $8 \%$ of the inventions had demonstrated manufacturing feasibility. Finally, the respondents to the survey indicated that $71 \%$ of licensed inventions would require further interaction between the inventor and licensee to develop a commercially viable product. Therefore, the increased licensing activity which has occurred since 1980 is consistent with the universities continuing their focus on basic research.

The data in the cited studies have two common characteristics. First, these studies relied upon university licensing and/or patenting activity as their primary measure of research at universities and colleges. Mowery et al. (2001) is a notable exception, but even this paper focuses on patent data. Second, due the vast number of patents and patent citations the studies use a relatively small sample of citations to study the quality of research or just concentrate on a few universities.

The view that the Bayh-Dole Act has led universities to alter R\&D activities is really an argument about the incentive to commit resources to basic research. Licensing and patenting data are arguably good measures of research output, but not necessarily good measures of research inputs. For example, unsuccessful research may not result in a patentable discovery. Mowery and Ziedonis (2002) show that the rate at which new discoveries receive patents is relatively low. Between 1984 and 1988 the rate was $21.9 \%$ for the University of California 
system and $25.1 \%$ for Stanford University. Therefore, the patent data may miss a significant amount of inventive activity at colleges and universities. Trajtenberg et al. (1997) discuss the conditions under which patent data maybe a useful proxy for the "basicness" of inventive activity. However, the measurement will always be with error. The National Science Foundation (NSF) surveys all doctorate granting institutions regarding their R\&D activity. That means research using $R \& D$ expenditure data should provide a useful robustness check to results based upon patent data.

The existing literature seems to operate with an implicit theoretical model in which universities are at least partially self-interested and respond to the incentive structure setup by the federal government. In this implicit model, universities pursue their publicly mandated goals of expanding scientific knowledge and educating students while simultaneously maximizing the revenues from patent licensing. The revenues from these licensing activities would then allow the university administrators to pursue their own university specific goals.

Thursby et al. (2001) report survey results of university Offices of Technology Transfer (OTT) which are consistent with this implicit model. Nearly $71 \%$ responded that royalties and licensing fees generated were extremely important in determining the success of the OTT. Another $61 \%$ indicated that the number of commercialized inventions was extremely important. Furthermore, Jensen and Thursby (2001) report that OTT managers and administrators view revenues as the most important objective of licensing activity. On the other hand, faculty gave the greatest weight to sponsored research. Friedman and Silberman (2003) show that administrators who want to encourage licensing activity and revenues have mechanisms to achieve this goal. In particular, administrators can increase the number of licenses and licensing income by increasing the royalty fees that faculty members receive. Lach and Schankerman (2003) using a panel of 102 universities during the 1990s find evidence consistent with this type of behavior.

Given this model, the Bayh-Dole Act may have influenced $R \& D$ activity in several ways. The Act made it easier for universities to license patents from $R \& D$ projects financed by the federal government to corporations. That means the government funded research became a potential source of patent licensing revenue which may have influenced university behavior. For example, Columbia altered its patent policies so that the university retained the patent rights and then shared royalties with the researcher. Now universities, like Columbia, had a stronger financial incentive to engage in research. Furthermore, the composition of R\&D projects may have changed. The lure of generating licensing revenue from applied research may have induced a redistribution of resources from basic to applied research. The universities may have then devoted the increased licensing revenue to both basic and applied research. This raises an interesting possibility: the level of resources devoted to basic R\&D may have increased even as the share of resources devoted to basic R\&D declined. Finally, industry may be more willing to partially fund $\mathrm{R} \& \mathrm{D}$ projects at colleges and universities. The colleges and universities usually retain the patent rights from projects funded by the federal government, but now firms can receive exclusive licensing agreements from the university on patents resulting from the research. This could further increase the resources available for research. It is also possible that industry used its growing relative importance in funding to shape research agendas.

This paper re-examines the issues raised in the existing literature using data on $R \& D$ activity to measure research input rather than using patents or licensing activity as a measure of research output. Therefore, one of the main contributions of this paper is to shift the focus of the literature from a noisy measure of research inputs to a much less noisy measure. In addition, the composition of $R \& D$ activity provides an alternative way to measure research quality. The approach in this paper provides a robustness check to the results in the existing literature.

\section{Data}

The NSF provides university R\&D data in two different forms. First, the university level dataset has information on university, government, and industry funding of $R \& D$ expenditures. This provides a rich university level panel data set to examine the effect of the Bayh-Dole Act on university R\&D activity. Second, the national level dataset has information on university $R \& D$ activity broken down by character of work: basic, applied or development. The national level data provides a useful means of examining how the Bayh-Dole Act influenced the composition of $R \& D$ activity. The national level data is aggregate data so there is one observation per year for each type of R\&D.

The national level R\&D data come from National Patterns of Research and Development Resources: 2002 Data Update published by the NSF and the university level data comes from its web based WebCASPAR system. The NSF (1998) indicates that the data come from surveys of all doctorate granting institutions, all historically black colleges and universities, and a random 
sample of remaining universities. As a result, there are approximately 500 universities in the survey sample. The gross domestic product (GDP) deflator used to calculate real quantities comes from the Bureau of Economic Analysis. The national level NSF data for R\&D extends from 1953 to 2002 while the university level data begins in 1972 and also goes until 2002.

The NSF changed its data collection methodology in 1998 to eliminate a double counting problem. Prior to 1998, the survey instructs the universities and colleges to "include research funds for which an outside organization, educational or other is a subrecipient." This means that prior to $1998 \mathrm{R} \& \mathrm{D}$ activity sometimes is counted twice: once by the recipient of the funds and a second time if the recipient "passes through" some funding to a sub-recipient. This practice changed in 1998 so the data from the pre-1998 period are not strictly comparable to the data starting in 1998. The Bayh-Dole Act passed in 1980 so searching for structural breaks requires using the pre-1998 data that contains the double counting. However, the amount of the "pass through" is relatively small (less than 5\% for years with data) so the presence of "pass through" is not likely to eliminate the usefulness of the pre-1998 data. In addition, both Figs. 1 and 2 show smooth growth trends for university research which suggests a relatively constant "pass through" effect over time. If the "pass through" effect is relatively constant over time then its presence should not bias the structural break tests in the following sections.

The NSF provides data for both R\&D performed by universities and colleges and R\&D funded by universities and colleges. R\&D performed by universities is R\&D activity that university researchers conduct regardless of whether the government, industry or the university funded the project. This would include R\&D activity by university researchers whose research is wholly or par-

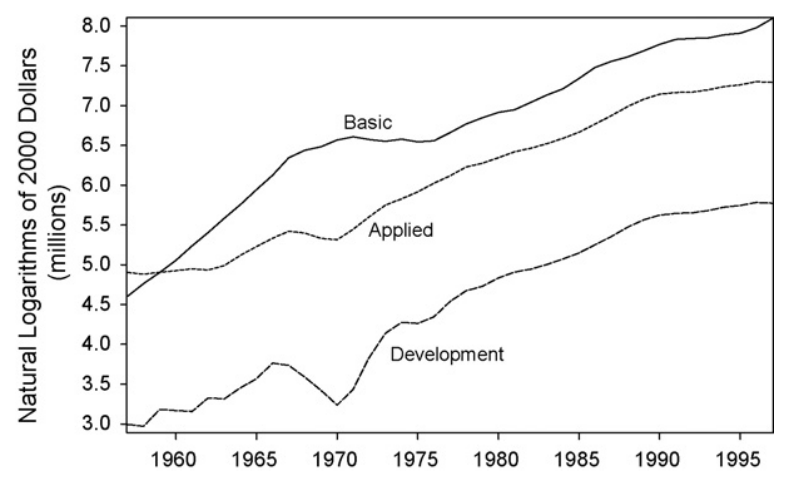

Fig. 1. Research and development expenditures funded by universities and colleges (natural logarithms of 2000 dollars).

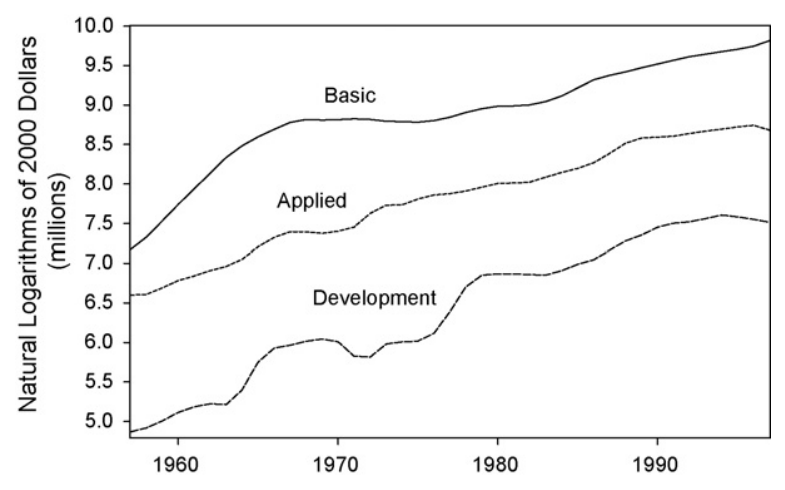

Fig. 2. Research and development expenditures performed by universities and colleges (natural logarithms of 2000 dollars).

tially funded by either government or industry sources. $R \& D$ funded by universities is $R \& D$ activity that the university supports through its own funds. This would exclude $R \& D$ activity by university researchers who are receiving funding from either government or industry sources. If a particular project received funding from government, industry, and university sources then only the part of the funding coming directly from the university would be included in this measure. Therefore, one can examine whether the Bayh-Dole Act influenced the incentive to fund $R \& D$ and/or the incentive to perform $R \& D$. The previous research focused on patent data which allows one to test for an effect of the Bayh-Dole Act on the results of inventive activity, but not the performance or funding of that activity.

\subsection{National level data}

\subsubsection{NSF data on character of work}

The NSF breaks the national level R\&D expenditures into three different types: basic, applied, and development. According to National Patterns of Research and Development Resources: 1998, universities and colleges are asked to classify R\&D expenditures using the following criteria:

"Basic Research. Within the Federal, university, and nonprofit sectors, basic research is defined as research directed toward increases in knowledge or understanding of the fundamental aspects of phenomena and of observable facts without specific application toward processes or products in mind."

“Applied Research. Within the Federal, university, and nonprofit sectors, applied research is defined as research directed toward gaining ... knowledge or understanding necessary for determining the means by which a recognized and specific need may be met." 
"Development. The NSF survey definition of development is ... the systematic use of the knowledge or understanding gained from research directed toward the production of useful materials, devices, systems or methods, including design and development of prototypes and processes. It excludes quality control, routine product testing, and production."

The NSF's definition of "basic research" corresponds closely to what the literature refers to as "basic research" while the literature's use of the term "applied research" corresponds to what the NSF defines as "applied research" plus "development." Because this paper uses NSF data, it is easier to adopt the NSF definitions for the remainder of the paper and use three rather than two categories of R\&D expenditures.

The NSF survey that obtains data for R\&D by character of work is the Survey of Research and Development Expenditures at Universities and Colleges (NSF, 2005). That survey asks respondents to classify R\&D expenditures into the above categories. If the $R \& D$ project is funded by a federal agency then the university is supposed to use the funding agencies classification of the project. The NSF does not audit whether universities use the funding agencies classification or the universities own. If the $R \& D$ project is funded by the university or industry then the university is supposed to use the above definitions to classify the research.

The federal government is a major source of funding for university R\&D so research activity at universities may just reflect the funding priorities of federal agencies. From 1953 to 1997, federal funding averaged 68\% of basic, $53 \%$ of applied, and $62 \%$ of development R\&D performed at universities. Therefore, federal research priorities should have a significant influence on university research.

Fig. 1 shows the time series for the natural logarithm of all three types of R\&D expenditures funded by universities and colleges. Fig. 2 shows the natural logarithm of all three types of $\mathrm{R} \& \mathrm{D}$ expenditures performed by universities and colleges. If the Bayh-Dole Act of 1980 caused a switch away from basic R\&D activities then one would expect the trend rate for basic R\&D to decline after 1981 and the trend rates for applied and development R\&D to increase. This clearly did not happen. To the extent that a decline in the trend rate of basic R\&D exists, it occurred sometime in the late 1960s or early 1970s. However, applied and development R\&D experience a similar decline so the decline does not appear to be a phenomena unique to basic research in universities and colleges.
The rest of this section more formally tests for a break in trend rates of growth among all three types of research after the passage of the Bayh-Dole Act of 1980. However, Figs. 1 and 2 tell the basic story: no significant break in trend growth rates occurs after the Act passes. These results suggest the Bayh-Dole Act is not associated with a major change in research activities at universities and colleges.

\subsubsection{Endogenous break point tests}

A simple way to check for structural breaks is to estimate a time-series model for each type of research and conduct a Chow test for a structural break in 1981. A break at that date would be consistent with the view that the Bayh-Dole Act changed the behavior of universities and colleges. However, this approach faces an important difficulty. If a structural break occurred at an earlier date (like in the late-1960s or early1970s) then the test may indicate a break in 1981 even though the break is not associated with the Bayh-Dole Act.

Therefore, this section uses the endogenous structural break test as described in Andrews (1993) to test for structural breaks in univariate autoregressive models for each type of research. The test consists of conducting a Chow breakpoint test over a range of dates and calculating the $F$-statistic from each Chow breakpoint test. The most likely date for a breakpoint is the date which produces the highest $F$-statistic. The distribution of this $F$-statistic is non-standard and Andrews (1993) provides critical values. The sample was "trimmed" so that Chow breakpoint tests are conducted over the inner $70 \%$ of the sample period (19631991).

The test equations are univariate autoregressive models. Figs. 1 and 2 suggest that each measure of research posses a distinct upward trend. This raises the issue of whether the data are trend stationary or difference stationary. Only the results for the trendstationary data specifications are reported in the paper. The results for the difference-stationary specifications produce very similar results and are available upon request.

Under the assumption that the data are trend stationary, the appropriate univariate model is one in levels of the form:

$y_{t}=\alpha+\lambda \operatorname{Trend}_{t}+\sum_{j=1}^{l} \beta_{j} y_{t-j}+\varepsilon_{t}$

where $\operatorname{Trend}_{t}$ is a linear time trend beginning in 1957 and the lag length, $l$, is chosen by Akaike and Schwarz 
Table 1

Endogenous breakpoint test results assuming trend-stationary data (period: 1957-1997)

\begin{tabular}{|c|c|c|c|c|c|c|}
\hline & \multicolumn{3}{|l|}{ Funded } & \multicolumn{3}{|c|}{ Performed } \\
\hline & Basic & Applied & Development & Basic & Applied & Development \\
\hline Lags in Model & 2 & 3 & 2 & 4 & 2 & 4 \\
\hline $\operatorname{Max} F$ & $5.287^{* * *}$ & $3.479^{*}$ & $5.183^{* * *}$ & $3.029^{* *}$ & $4.128^{* *}$ & 2.035 \\
\hline Date of $\max F$ & 1968 & 1971 & 1965 & 1964 & 1976 & 1966 \\
\hline
\end{tabular}

Note: ${ }^{* * *}$ Indicates significant at the $99 \%$ level. ${ }^{* *}$ Indicates significant at the $95 \%$ level. * Indicates significant at the $90 \%$ level. A break occurs at the date indicated only if the max $F$-statistic is statistically significant. Lag length determined by Akaike and Schwarz information criteria. There are 41 observations for the full sample.

information criteria. The model is estimated over the 1957-1997 time period using ordinary least squares for each type of research funded by and performed by universities and colleges.

Table 1 shows the results of the endogenous break point tests for R\&D funded and performed by universities and colleges under the assumption that the data are trend stationary. Andrews (1993) indicates that the endogenous break point test is not strictly valid with trending regressors. However, the results of endogenous break point tests are similar regardless of whether one assumes that the data are difference or trend stationary. The first three columns of Table 1 show the results for R\&D funded by universities and colleges. The results suggest that all three series experience a structural break with the most likely date for the break with basic R\&D is 1968 , for applied $R \& D$ is 1971 , and for development $R \& D$ is 1965 . The next three columns of Table 2 show the results for R\&D performed by universities and colleges assuming the data are trend stationary. The results suggest a structural break for basic R\&D in 1964, a structural break for applied R\&D in 1976, but no structural break for development R\&D.

Overall none of the results support the view that a structural break occurs for any type of research during the period after the passage of the Bayh-Dole Act of 1980. It is very difficult to reconcile this result with the claim that the Bayh-Dole Act led universities and colleges to de-emphasize basic R\&D in favor of development R\&D.

\subsubsection{Further tests}

The next test is to estimate a model for all three types of $R \& D$ funded and performed by universities and colleges which allow for a break in 1981. The results further establish that the behavior of universities is not consistent with the view that the Bayh-Dole Act encouraged universities to de-emphasize basic research. Under the assumption that the data are trend stationary, the appro- priate model is

$$
\begin{aligned}
y_{t}= & \alpha+\lambda_{1} \operatorname{Trend}_{t}+\lambda_{2} \text { Trend }_{t}+\lambda_{3} \text { TrendBayhDole }_{t} \\
& +\sum_{i=1}^{l} \beta_{j} y_{t-j}+\varepsilon_{t} .
\end{aligned}
$$

Trend $1_{t}$ is a linear time trend beginning in 1957 , Trend $2_{t}$ is a linear trend for the endogenous break (if any) determined in the previous section, TrendBayhDole ${ }_{t}$ is a linear trend beginning in 1981 after the passage of the Bayh-Dole Act, and the lag length, $l$, is the same as with the endogenous breakpoint test.

Table 2 shows the results of estimating Eq. (2) with ordinary least squares. The key parameter, $\lambda_{3}$, is statistically significant in four of the six models. For R\&D funded by universities and colleges, the results suggest that the trend growth rate increased by $0.80 \%$ per year for basic R\&D after the passage of the Bayh-Dole Act while the trend growth rate for development $R \& D$ declined by a statistically insignificant $0.62 \%$ per year. The results are similar when one looks at $R \& D$ performed in universities and colleges. The trend growth rate for basic R\&D performed by universities and colleges increased by $0.46 \%$ per year and the growth rate for development R\&D performed by universities and colleges decreases by $0.66 \%$ per year. These results are rather large, especially the cumulative effect over several years, however the sign of the estimated parameters are the opposite of what one would expect if the Bayh-Dole Act led universities to shift resources from basic R\&D towards development R\&D.

\subsubsection{Industry funded $R \& D$}

The aggregate university R\&D data are not consistent with the claim that universities have de-emphasized basic research in favor of development research. Rather the results are consistent with the findings that the quality of patent data did not decline after the Bayh-Dole Act. Nonetheless, the Act might have resulted in greater industry influence over university and college research 


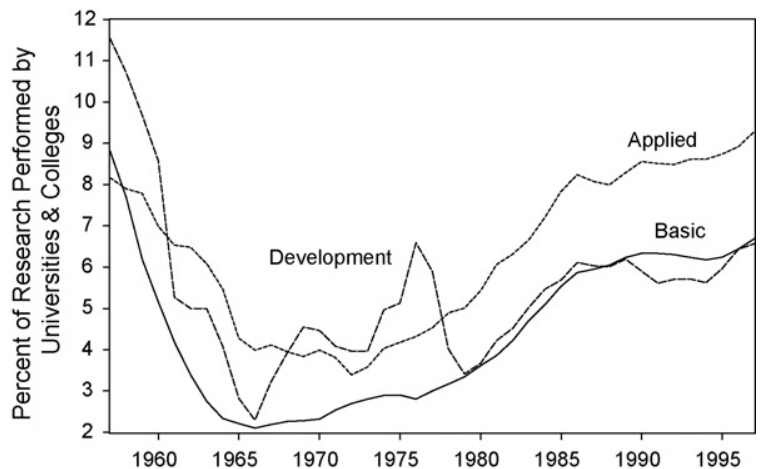

Fig. 3. Industry funded research and development as a share of university and college research (percentage points).

if the Act led industry to fund a greater percentage of university and college research. If this influence led universities to alter the types of basic R\&D projects then this could result in a decline in research quality of basic $R \& D$ projects.

Fig. 3 shows that industry funding as a percentage of R\&D performed by universities and colleges fell throughout the 1960s, bottomed out in the late-1960s or early-1970s, and has risen since then. Industry funding of applied R\&D is near the highpoint of the sample, but industry funding of basic and development $R \& D$ are about one-half the highpoint in the sample. In addition, industry started funding a growing percentage of university and college research starting in the late-1960s or early-1970s. This means that any growing industry influence predates the Bayh-Dole Act by a decade or more. It is also interesting to note that industry financing of university research is a relatively small percentage of the total. For most years, industry funding of research is less than $10 \%$ of the total amount of research and for many years it is significantly less than even that low level.

It is also possible to use endogenous breakpoint tests to see if there is a break in the time-series behavior of industry funding of university research at the time of

\section{Table 3}

Endogenous breakpoint test results for industry funding of university and college research (period: 1957-1997)

\begin{tabular}{llll}
\hline & Basic & Applied & Development \\
\hline Lags in model & 2 & 2 & 2 \\
Max $F$ & $5.685^{* *}$ & $4.377^{*}$ & 1.195 \\
Date of max $F$ & 1977 & 1971 & 1967
\end{tabular}

Note: ${ }^{* * *}$ Indicates significant at the $99 \%$ level. ${ }^{* *}$ Indicates significant at the $95 \%$ level. *Indicates significant at the $90 \%$ level. A break occurs at the date indicated only if the max $F$-statistic is statistically significant. Lag length determined by Akaike and Schwarz information criteria. There are 41 observations for the full sample. 
Table 4

Effect of Bayh-Dole Act on industry financing of university and college research

\begin{tabular}{|c|c|c|c|}
\hline & Basic & Applied & Development \\
\hline$\alpha$ & $0.103(0.200)[0.610]$ & $1.321(0.463)[0.007]$ & $4.423(1.436)[0.004]$ \\
\hline$\gamma_{1}$ & $0.143(0.146)[0.335]$ & $-0.506(0.239)[0.041]$ & $-2.049(0.842)[0.020]$ \\
\hline$\gamma_{2}$ & $0.212(0.085)[0.018]$ & $0.799(0.239)[0.002]$ & $0.654(0.325)[0.052]$ \\
\hline$\beta_{1}$ & $1.771(0.130)[0.000]$ & $1.199(0.152)[0.000]$ & $0.935(0.162)[0.000]$ \\
\hline$\beta_{2}$ & $-1.351(0.260)[0.000]$ & $-0.388(0.133)[0.006]$ & $-0.006(0.189)[0.974]$ \\
\hline$\beta_{3}$ & $0.845(0.253)[0.002]$ & & $-0.381(0.121)[0.003]$ \\
\hline$\beta_{4}$ & $-0.336(0.114)[0.006]$ & & \\
\hline$R^{2}$ & 0.995 & 0.972 & 0.827 \\
\hline Adjusted- $R^{2}$ & 0.994 & 0.969 & 0.802 \\
\hline Standard error of regression & 0.143 & 0.338 & 0.848 \\
\hline Standard deviation of $y_{\mathrm{t}}$ & 1.836 & 1.924 & 1.906 \\
\hline Mean of $y_{t}$ & 4.437 & 6.320 & 5.454 \\
\hline
\end{tabular}

Dependent variable: natural logarithm of R\&D expenditures; method: ordinary least squares; period: 1957-1997 (41 observations). Note: Coefficient estimate appears first with standard errors in parentheses and $p$-values in brackets.

the Bayh-Dole Act. Under the assumption that industry funding as a percentage of university performed research is stationary, the appropriate time-series model is

$y_{t}=\alpha+\sum_{j=1}^{l} \beta_{j} y_{t-j}+\varepsilon_{t}$

where $y$ is industry funding as a percentage of university performed research and $l$ is the lag length determined by Akaike and Schwarz information criteria and $l$ is allowed to vary across the three types of research. Table 3 shows the results of the endogenous breakpoint tests for each type of research. The results indicate that breaks do occur for basic and applied research, but the breaks for basic and applied research occur several years prior to the passage of the Bayh-Dole Act. Once again, any evidence for a break occurs prior to the passage of the Bayh-Dole Act.

To further test for a structural break after the passage of the Bayh-Dole Act, the following model was estimated for each type of research

$y_{t}=\alpha+\gamma_{1}$ Break $_{t}+\gamma_{2}$ BayhDole $_{t}+\sum_{j=1}^{l} \beta_{j} y_{t-j}+\varepsilon_{t}$

which is analogous to earlier equations except $y$ is assumed to be stationary rather than trend stationary. If the Bayh-Dole Act led to increased industry influence on university research then one would expect that $\gamma_{2}>0$ for at least one of the three types of research. Table 4 shows the results of estimating Eq. (4) for each type of research. The results show that $\gamma_{2}>0$ and statistically significant for all three types of research. The estimates of $\gamma_{2}$ range from a low of $0.212 \%$ for basic research to a high of $0.799 \%$ for applied research which are relatively small percentages of research performed by universities. Moreover, when one considers the fact that industry's share of funding for all three types of research bottomed in the late-1960s and then rose during the 1970s, the Bayh-Dole Act seems to have just reinforced an existing trend of rising industry funding.

\section{University level data}

The national level data yield interesting results, but it is possible that these data mask trends occurring at the individual universities or amongst groups of universities. The university level data do not distinguish among types of R\&D activities (basic, applied, or development); therefore, I cannot estimate Eqs. (1)-(3) at the level of individual universities for each separate type of $R \& D$. However, I can estimate models for industry funding of R\&D and examine whether the Bayh-Dole Act or other institutional changes have caused changes in R\&D activity. I choose to estimate models analogous to Eq. (3) for industry financed $R \& D$, university financed $R \& D$, and $R \& D$ performed at colleges and universities. This allows me test the claim that the Bayh-Dole Act led universities to perform more $\mathrm{R} \& \mathrm{D}$, devote more resources to $R \& D$, or led industry to increase its funding of university research. ${ }^{1}$

The university level data set contains information on 283 colleges and universities for the 1976-1997 time

\footnotetext{
${ }^{1}$ I estimated a model similar to Eq. (4) and found that industry's share of R\&D financing increased by about $0.7 \%$. This is consistent with the results from the previous section.
} 
period for nearly 6000 observations. ${ }^{2}$ Only colleges and universities with R\&D data for the pre- and post-1981 time period were included in the data set and some colleges and universities did not report data for the full sample period. As a result, the panel is unbalanced. The sample does cover a wide range of types of colleges and universities: 88 Research I; 37 Research II; 45 Doctoral I; 40 Doctoral II; 23 Masters I; 0 Masters II; 4 Baccalaureate I; 0 Baccalaureate II; 30 Medical; and 16 other.

\subsection{Bayh-Dole Act}

Under the assumption that the data are trend stationary, the appropriate univariate model is one in levels of the form:

$$
\begin{aligned}
y_{i t}= & \alpha_{i}+\lambda_{1} \operatorname{Trend}_{t}+\lambda_{2} \text { TrendBayhDole }_{t} \\
& +\sum_{j=1}^{l} \beta_{j} y_{i t-j}+\varepsilon_{i t}
\end{aligned}
$$

where $y_{i t}$ is the natural logarithm of R\&D performed or $R \& D$ funded by colleges and universities or industry, is a linear time trend beginning in 1976, TrendBayhDole ${ }_{t}$ is a linear trend beginning in 1981 after the passage of the Bayh-Dole Act. The model is estimated over the 1976-1997 time period and the lag length, $l$, is chosen by Akaike and Schwarz information criteria. In this specification, the passage of the Bayh-Dole Act can influence the trend growth rate of $R \& D$ expenditures (if $\lambda_{2}$ is statistically significant).

The university fixed effect $\left(\alpha_{i}\right)$ measure differences in the level of R\&D activity across universities which are fixed for individual universities, but constant over time. For example, initial levels of institutional support for research, initial levels of federal funding etc. are all included in the university fixed effects. Eq. (5) is a dynamic panel model and the presence of lagged dependent variables raises the possibility that the university fixed effects (the $\alpha \mathrm{s}$ ) are correlated with the contemporaneous error term. Therefore, I estimate the first-difference version of Eq. (5) which eliminates the university fixed effects. This version of the model is

$$
\begin{aligned}
\Delta y_{i t}= & \lambda_{1} \Delta \operatorname{Trend}_{t}+\lambda_{2} \Delta \text { TrendBayhDole }_{t} \\
& +\sum_{j=1}^{l} \beta_{j} \Delta y_{t-j}+\eta_{i t}
\end{aligned}
$$

\footnotetext{
2 The data for the 1953-1972 period exists, but is not publicly available. In addition, many universities are missing data for the year 1978. These universities are dropped from the data set.
}

where $\eta_{i t}=\Delta \varepsilon_{i t}$. Again the relevant test is whether $\lambda_{2}$ is statistically significant.

Table 5 shows the results from estimating Eq. (6). The results do not suggest that the passage of the Bayh-Dole Act is associated with any statistically significant change in $R \& D$ activity at colleges and universities. None of the estimates for $\lambda_{2}$ are statistically significant at the even the $10 \%$ level of significance. To the extent that there is a break in trend, it is towards less industry funding (a 1.6\% deceleration in trend growth) and university funding (a $4.25 \%$ deceleration in trend growth) of R\&D activity. This is the exact opposite of what one would expect if the Bayh-Dole Act increased the incentive to fund and perform university research.

The results in Table 5 include all categories of universities from research intensive universities to liberal arts colleges. Less research intensive universities may not respond to the Bayh-Dole Act because of the nature of the research that they do. Therefore, Table 6 shows estimates of $\lambda_{2}$ disaggregating by Carnegie classification. The results again show no statistically significant change in the trend growth rate of R\&D activity after the passage of the Bayh-Dole Act. This is true regardless of whether one looks at performance of $R \& D$ or funding of $R \& D$ by industry and the university itself.

\subsubsection{Robustness checks}

It may take time for colleges and universities to respond to the incentives that the Bayh-Dole Act created. For example, it takes time to establish administrative offices to market the results of research. If this is the case then a break in the trend growth rate may not occur at the time of the Bayh-Dole Act even if the Act eventually leads to a change in behavior. I conduct two tests of this claim. First, I estimate Eq. (6) for two subgroups of universities. The first subgroup consists of the 36 universities with an Office of Technology Transfer (OTT) established prior to the passage of the Bayh-Dole Act. Presumably these universities have the institutional structure in place to take advantage of the incentives that the Act creates. The second subgroup consists of the 118 universities which created an OTT after the Act. The Association of University Technology Managers (AUTM) provides information on the date at which its members establish an OTT. The results in Table 7 indicate that there is no change in research activity for those universities which established OTT before the Bayh-Dole Act. The Bayh-Dole Act is not associated with a change in behavior even for those universities best position to take advantage of the altered incentives. In addition, if there is a change in behavior it is one towards reduced industry financing and performance of 
Table 5

Effect of Bayh-Dole Act using university level data

\begin{tabular}{llll}
\hline & Funded & & \multirow{2}{*}{ Performed } \\
\cline { 2 - 3 } & Industry & University & $5.284(0.878)[0.000]$ \\
$\lambda_{1}$ & $12.358(2.270)[0.000]$ & $13.695(2.844)[0.000]$ & $1.389(0.844)[0.101]$ \\
$\lambda_{2} \beta_{1}$ & $-1.578(2.410)[0.513]$ & $-4.248(2.956)[0.151]$ & $-0.085(0.033)[0.011]$ \\
$\beta_{2}$ & $-0.173(0.028)[0.000]$ & $-0.211(0.030)[0.000]$ & $-0.062(0.063)[0.324]$ \\
$\beta_{3}$ & $-0.104(0.019)[0.000]$ & $-0.092(0.018)[0.000]$ & $-0.052(0.028)[0.060]$ \\
$R^{2}$ & $-0.077(0.019)[0.000]$ & $-0.007(0.017)[0.000]$ & 0.013 \\
Adjusted- $R^{2}$ & 0.039 & 0.047 & 0.012 \\
Standard error of regression & 0.038 & 0.046 & 24.295 \\
Standard deviation of $y_{\mathrm{t}}$ & 51.504 & 53.798 & 24.442 \\
Mean of $y_{t}$ & 52.526 & 55.097 & 5.381 \\
Observations & 7.894 & 7.578 & 5905 \\
\hline
\end{tabular}

Dependent variable: natural logarithm of R\&D expenditures; method: first differences; period: 1977-1997. Note: Coefficient estimates appear first with standard errors in parentheses and $p$-values in brackets. Standard errors are corrected for both heteroskedasticity and autocorrelation.

Table 6

Effect of Bayh-Dole Act using university level data by carnegie classification

\begin{tabular}{|c|c|c|c|}
\hline \multirow[t]{3}{*}{ Carnegie classification } & \multicolumn{3}{|l|}{ Estimates of $\lambda_{2}$} \\
\hline & \multicolumn{2}{|l|}{ Funded } & \multirow[t]{2}{*}{ Performed } \\
\hline & Industry & University & \\
\hline Research & $-2.809(2.491)[0.260]$ & $-4.138(3.860)[0.284]$ & $0.451(0.660)$ [0.495] \\
\hline Doctoral & $-2.949(5.903)[0.618]$ & $-4.066(4.957)[0.412]$ & 2.928 (2.059) [0.155] \\
\hline Masters & $-3.927(10.135)$ [0.699] & $-7.421(14.301)[0.604]$ & $-3.059(4.693)[0.515]$ \\
\hline Medical & 1.223 (7.382) [0.869] & $-7.247(18.935)[0.702]$ & 2.933 (1.954) [0.134] \\
\hline
\end{tabular}

Dependent variable: natural logarithm of R\&D expenditures; method: first differences; period: 1976-1997. Note: Coefficient estimate for $\lambda_{2}$ appear first with standard errors in parentheses and $p$-values in brackets. Standard errors are corrected for both heteroskedasticity and autocorrelation. There are 2625 observations for Researches I and II universities, 1780 observations for Doctorals I and II universities, 473 observations for Masters I and II universities, and 625 for Medical universities.

R\&D at universities which established an OTT after the passage of the Act.

As another check, I re-estimate Eq. (6) but use the establishment of an OTT as the break date. If the establishment of an OTT is the critical event which altered university behavior then one would expect a break in trend growth rate at that time. The results are contained in Table 8. It looks like universities started to perform less R\&D after establishing an OTT which is not what one would expect if universities were responding to incentives in the Bayh-Dole Act. In addition, industry funds less R\&D at universities after the Act. Again this is not

Table 7

Office of technology transfer and the Bayh-Dole Act

\begin{tabular}{llrr}
\hline When established OTT & \multicolumn{2}{l}{ Estimates of $\lambda_{2}$} & \\
\cline { 2 - 4 } & \multicolumn{1}{l}{ Funded } & Performed \\
\cline { 2 - 4 } & \multicolumn{1}{l}{ Industry } & University & $-0.018(1.389)[0.990]$ \\
\hline Before Bayh-Dole & $-3.235(6.006)[0.590]$ & $0.269(4.369)[0.951]$ & $1.495(0.869)[0.086]$ \\
After Bayh-Dole & $-5.765(2.741)[0.036]$ & $-4.229(4.951)[0.393]$ &
\end{tabular}

Dependent variable: natural logarithm of R\&D expenditures; method: first differences; period: 1976-1997. Note: Coefficient estimate for $\lambda_{2}$ appear first with standard errors in parentheses and $p$-values in brackets. Standard errors are corrected for both heteroskedasticity and autocorrelation. There are 36 universities (for a total of 751 observations) which established an OTT prior to the passage of the Bayh-Dole Act. There are 118 universities (for a total of 2463 observations) which established an OTT after the passage of the Bayh-Dole Act. 
Table 8

Office of technology transfer specific trend

\begin{tabular}{|c|c|c|c|}
\hline \multirow[t]{3}{*}{ Trend } & \multicolumn{3}{|l|}{ Estimates of $\lambda$} \\
\hline & \multicolumn{2}{|l|}{ Funded } & \multirow[t]{2}{*}{ Performed } \\
\hline & Industry & University & \\
\hline OTT & $-0.378(0.095)[0.000]$ & $-2.986(1.926)[0.121]$ & $-0.898(0.393)[0.022]$ \\
\hline
\end{tabular}

what one would expect if the Bayh-Dole Act significantly altered university research behavior.

\section{Conclusion}

This paper examined the influence of the Bayh-Dole Act on the level of academic research, the composition of academic research, and the relative importance of industry funding of academic research. The claim that the Bayh-Dole Act influenced the research environment at universities is first and foremost a claim regarding research inputs not research output at universities and colleges. A measure of research input (like R\&D expenditures) is the most appropriate measure for testing that claim. In addition, the surveys that the NSF conducts arguably provide more complete coverage of university research than the existing literature's use of patent data. This paper shed new light on the issue by using time-series models to examine R\&D inputs. The main conclusion of the paper is that any changes in university research which do occur happen before the passage of the Bayh-Dole Act and are often the opposite of what one would expect if the Act had a significant influence on incentives.

In addition to the Bayh-Dole Act there were a number of changes in the legal environment involving patents in the early 1980s. For example, in 1980 the Supreme Court decision in Diamond vs. Chakrabarty reaffirmed the patentability of life forms and in 1983 congress altered the appeals process for patent cases by creating the Court of Appeals for the Federal Circuit. One of the goals was to streamline the resolution of patent disputes which should reduce the uncertainty involving patent rights. Both of these changes to the legal environment happened at about the same time as the Bayh-Dole Act and may cause a structural break which shows up as statistically significant estimates of $\lambda_{2}$. This makes it difficult to interpret any statistically significant results as being due to the Bayh-Dole Act alone. However, this paper finds very little effect of the Bayh-Dole Act using either the university level or national level data. To the extent that changes occur they are the opposite of the ones expected from the institutional changes during this period. In addition, any change in research activity at universities seems to occur before any of these institutional changes.

The results based upon the national level data also provide valuable information. First, the national level data provides information on the composition of $R \& D$ expenditures which is an alternative way to measure the quality of research. Second, the national level data is available for a longer time span and allows us to test whether changes in the importance of industry financing started prior to the passage of the Bayh-Dole Act.

The results using this data suggest a shift towards greater industry financing starting during the 1970s which pre-dates the Bayh-Dole Act. There is also a shift towards more basic R\&D starting in the 1970s. Neither the changes found using the national level or university level data are consistent with the view that the Bayh-Dole Act altered university research behavior.

The results in this paper are most consistent with a change in the university research environment starting in the 1970s. This agrees with the results of Mowery et al. (2001), Mowery and Ziedonis (2001), and Sampat et al. (2003). These papers and the current paper are consistent with the view that changing technological possibilities associated with biomedical and pharmaceutical research during the 1970s led to the change in patenting and $R \& D$ behavior of universities and colleges.

Why no effect? There are two possible reasons. First, the effect of the Act on incentives might be small since universities could patent (albeit with more difficulty) before the Act. Second, peer reviews of federal grants may have acted as a check on the ability of faculty and universities to alter the types of $R \& D$ projects they were performing. The Bayh-Dole Act is just one of many factors influencing university $R \& D$. The chief alternate influence is federal funding of university research. As long as the federal government is focused on basic R\&D 
and chooses to fund basic $R \& D$ projects then universities will continue to do basic R\&D.

\section{References}

Andrews, D., 1993. Tests for parameter instability and structural change with unknown change point. Econometrica, 821-856.

Association of University Technology Managers, 2004. AUTM Licensing Survey: Fiscal Year 2003. AUTM, Norwalk, CT.

Coupe, T., 2003. Science is golden: academic R\&D and university patents. Journal of Technology Transfer, 31-46.

Friedman, J., Silberman, J., 2003. University technology transfer: do incentives, management, and location matter? Journal of Technology Transfer, 17-30.

Henderson, R., Jaffe, A., Trajtenberg, M., 1998. Universities as a source of commercial technology: a detailed analysis of university patenting, 1965-1988. The Review of Economics and Statistics, $119-127$.

Jensen, R., Thursby, M., 2001. Proofs and prototypes for sale: the licensing of university inventions. American Economic Review, 240-259.

Lach, S., Schankerman, M., 2003. Incentives and invention in universities. National Bureau of Economic Research Working Paper \#9727.

Mowery, D., Nelson, R., Sampat, B., Ziedonis, A., 2001. The growth of patenting and licensing by U.S. universities: an assessment of the effects of the Bayh-Dole Act of 1980. Research Policy, 99-119.

Mowery, D., Ziedonis, A., 2001. Numbers, quality, and entry: how has the Bayh-Dole Act affected U.S. university patenting and licensing? In: Adam Jaffe, Josh Lerner, Scott Stern (Eds.), Innovation Policy and the Economy, vol. 1, pp. 187-220.

Mowery, D., Ziedonis, A., 2002. Academic patent quality and quantity before and after the Bayh-Dole Act in the United States. Research Policy, 399-418.

National Science Foundation, 1998. National Patterns of Research and Development Resources. NSF, Washington, DC.

National Science Foundation, 2002. National Patterns of Research and Development Resources: 2002 Data Update. NSF, Washington, DC.

National Science Foundation, 2005. Survey of Research and Development Expenditures at Universities and Colleges. NSF, Washington, DC.

Sampat, B., Mowery, D., Ziedonis, A., 2003. Changes in university patent quality after the Bayh-Dole Act: a re-examination. International Journal of Industrial Organization, 1371-1390.

Stokes, D., 1997. Pasteur's Quadrant: Basic Science and Technological Innovation. Brookings Institution Press, Washington, DC.

Thursby, J., Jensen, R., Thursby, M., 2001. Journal of Technology Transfer, 59-72.

Trajtenberg, M., Henderson, R., Jaffe, A., 1997. University versus corporate patents: a window on the basicness of invention. Economics of Innovation and New Technology, 19-50. 